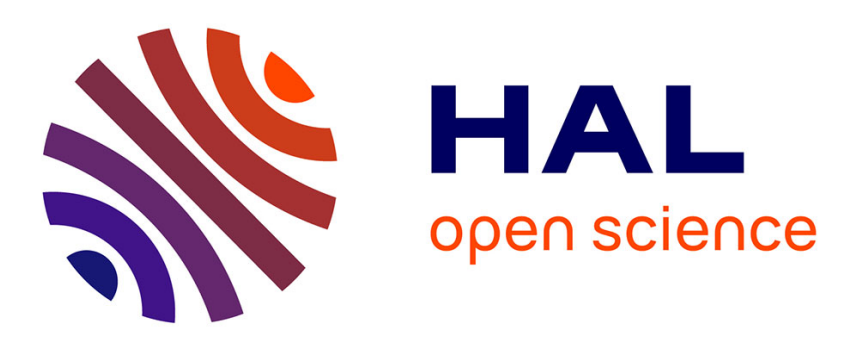

\title{
On the experimental determination of growth and damping rates for combustion instabilities
}

Daniel Mejia, Maxence Miguel-Brebion, Laurent Selle

\section{To cite this version:}

Daniel Mejia, Maxence Miguel-Brebion, Laurent Selle. On the experimental determination of growth and damping rates for combustion instabilities. Combustion and Flame, 2016, 169, pp.287-296. 10.1016/j.combustflame.2016.05.004 . hal-01333028

\section{HAL Id: hal-01333028 \\ https://hal.science/hal-01333028}

Submitted on 28 Jun 2016

HAL is a multi-disciplinary open access archive for the deposit and dissemination of scientific research documents, whether they are published or not. The documents may come from teaching and research institutions in France or abroad, or from public or private research centers.
L'archive ouverte pluridisciplinaire HAL, est destinée au dépôt et à la diffusion de documents scientifiques de niveau recherche, publiés ou non, émanant des établissements d'enseignement et de recherche français ou étrangers, des laboratoires publics ou privés. 


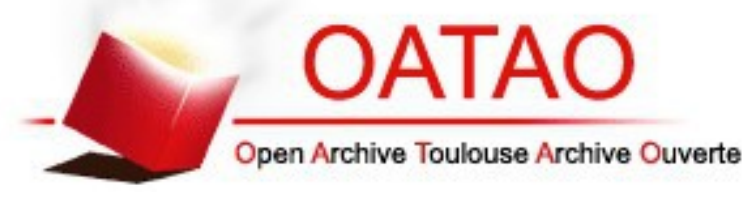

\section{Open Archive TOULOUSE Archive Ouverte (OATAO)}

OATAO is an open access repository that collects the work of Toulouse researchers and makes it freely available over the web where possible.

This is an author-deposited version published in : http://oatao.univ-toulouse.fr/ Eprints ID : 15910

To link to this article : DOI:10.1016/j.combustflame.2016.05.004 URL : http://dx.doi.org/10.1016/j.combustflame.2016.05.004

To cite this version : Mejia, Daniel and Miguel-Brebion, Maxence and Selle, Laurent $O n$ the experimental determination of growth and damping rates for combustion instabilities. (2016) Combustion and Flame, vol. 169. pp. 287-296. ISSN 0010-2180

Any correspondence concerning this service should be sent to the repository administrator: staff-oatao@listes-diff.inp-toulouse.fr 


\title{
On the experimental determination of growth and damping rates for combustion instabilities
}

\author{
D. Mejia*, M. Miguel-Brebion, L. Selle \\ Institut de Mécanique des Fluides de Toulouse (IMFT) - Université de Toulouse, CNRS-INPT-UPS, Toulouse, France
}

Keywords:

Combustion instabilities

Flame Transfer Function

Growth rate

Damping rate

\begin{abstract}
A B S T R A C T
This paper presents four experimental methods for the evaluation of growth rates of combustion instabilities. A systematic investigation is conducted on a laminar slot burner with five operating points (two stable and three unstable). The accuracy of the methods is assessed by cross comparison and the use of three different flow variables as input: velocity, pressure and heat release rate fluctuations. Finally, the experimental determinations of the growth rates are compared to the prediction of a low-order acoustic model fed with a Flame Transfer Function.
\end{abstract}

\section{Introduction}

Combustion instabilities (CI) are a major problem for the design and operation of power-generation systems such as gas turbines, aeronautical engines and rocket engines [1]. The constructive coupling between acoustic waves and unsteady heat release rate constitutive of $\mathrm{CI}$, is responsible for loss of performance, restriction under operating conditions and sometimes catastrophic failures. The challenge for understanding and predicting $\mathrm{CI}$ lies in the multiplicity of physical phenomena involved in the unstable loop [2]: acoustics, vortex dynamics, mixing, turbulence, chemistry, two-phase flows, etc. One of the canonical configurations for the study of $\mathrm{Cl}$ is the laminar premixed flame, which has been extensively scrutinized [3-6]. Despite its apparent simplicity, this flame contains one of the main physical mechanisms driving CI: the dynamic interaction between acoustics, vortical structures in the flow field and the flame front. Comparative studies of conical, V-shaped and triangular flames gives insight into the mechanisms driving the overall response of the flame to acoustic perturbations [7]. The crux of the matter for the prediction of $\mathrm{CI}$ is to model this response, which is often achieved through a so-called Flame Transfer Function (FTF), relating the unsteady heat release rate of the flame, $\dot{q}^{\prime}$, to the incident acoustic velocity perturbation, $v^{\prime}$. In many of the above mentioned configurations, reasonably accurate analytical models for the FTF can be derived [6,8]. For realistic combustion devices, the FTF must be measured experimentally [9-11] or com-

\footnotetext{
* Corresponding author.

E-mail address: dmejia@imft.fr, danielmejia83@gmail.com (D. Mejia).
}

puted with high-fidelity unsteady 3D numerical simulations [1214].

For the design of stable combustion devices, a trial-and-error experimental approach is very costly so that alternatives using numerical simulation are sought. The first option, which may be called a brute-force approach is to solve the reacting Navier-Stokes equations over the whole configuration. Large-Eddy Simulation, for example, has shown its potential for this task $[15,16]$. The computational cost of a single simulation is however so large that the exploration of the whole range of operating conditions or design variations is impractical. An alternative is to solve only for acoustic perturbations and model the flame via the FTF: the resulting tool may be called a thermoacoustic code. Whether the equations be Linearized Euler or Helmholtz, in complex 3D geometries or 1D network models, the methodology is usually computationally lean and has shown its ability to predict stability maps [10,17-20]. The typical output of a thermoacoustic solver is threefold: (1) the frequency of the instability, (2) the shape of the associated pressure and velocity fields and (3) the linear growth rate of individual eigenmodes.

Because the impact of the flame as an active acoustic source is usually small, the prediction of eigenfrequencies and mode shapes is not a difficult task. The determination of the growth rates is more subtle as it requires a precise evaluation of the flame response (with a FTF for example), the fluxes through the boundaries (by specifying the impedances) and the sources of internal dissipation (through friction at the walls and transfer from acoustics to vorticity). And yet, a precise determination of the linear growth rate is crucial for the design and safe operation of an engine. Indeed, even if a given operating point is observed as stable, it is 


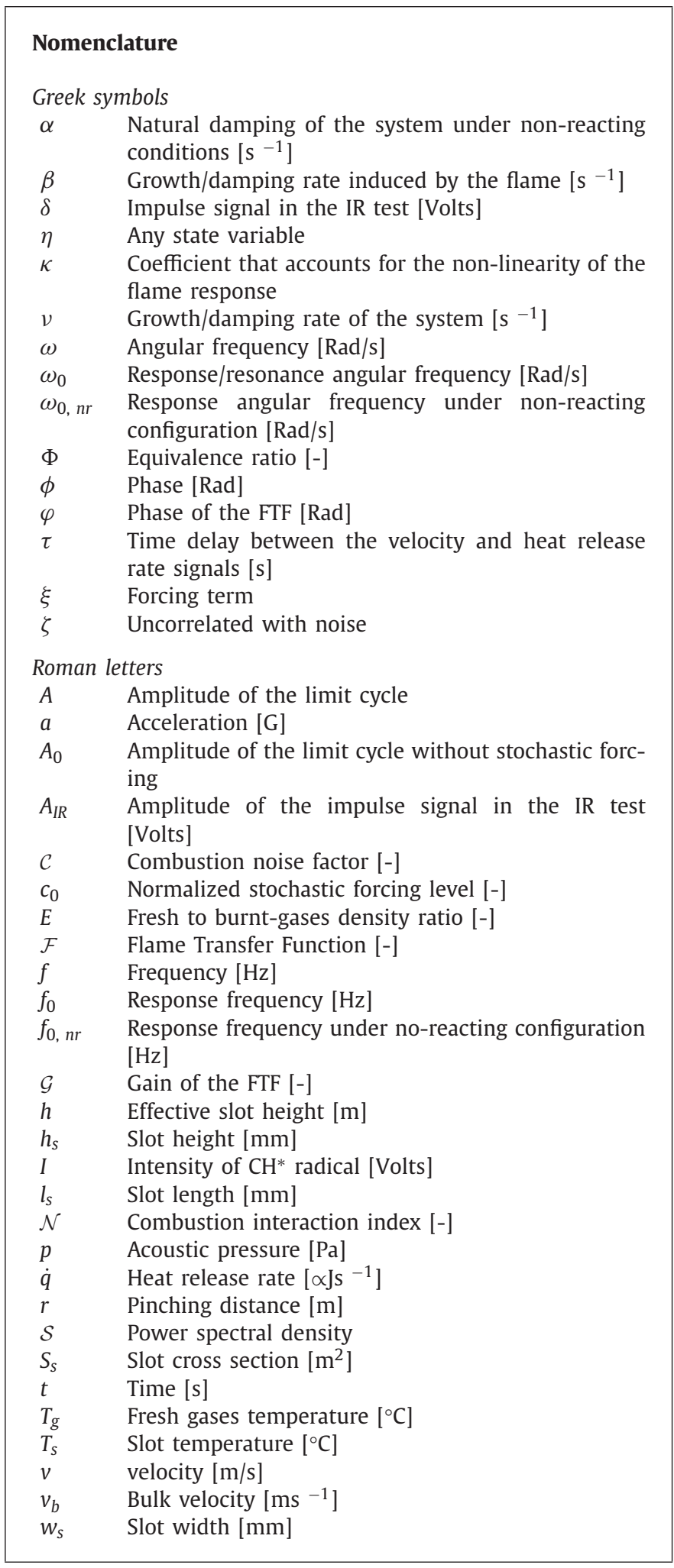

useful to know how far from stability it is so that small changes (manufacturing variations, aging through mechanical and thermal stress, variations in fuel properties, etc.) do not trigger a $\mathrm{Cl}$.

The objective of the present work is to present various experimental techniques that can be used to measure the growth rate of stable or unstable modes with the intent to serve as a validation for thermoacoustic solvers. The manuscript is organized as follows: First, in Section 2 a general model for a second-order dynamic system is presented. This model is the starting point to derive the particular solutions to the corresponding four damping/growth rate identification methods. Then, the experimental setup and diagnostics are presented in Section 3. The experimental results for each of the four identification methods is then discussed in Section 4. Finally, a low-order model is derived in Section 5 and compared to the results of Section 4 for the validation of its ability to predict the linear growth rate of CIs.

\section{Theoretical model}

The objective of this work is the evaluation of the growth rate for a specific mode and as explained in [19,21], around a given eigenmode of angular frequency $\omega_{0}$, it is a valid assumption to consider that the thermoacoustic system obeys a second-order differential equation of the form:

$\ddot{\eta}-f(\eta, \dot{\eta})+\omega_{0}^{2} \eta=\xi$

This formulations follows that of [21], where $\eta$ represents any state variable and $f$ is a non-linear function of $\eta$ and its first derivative $\dot{\eta}$, which accounts for internal dissipation, fluxes of acoustic energy at the boundaries and the contribution of unsteady combustion, i.e. the flame. $\xi$, corresponds to a forcing term due to an external device such as a loudspeaker. In the present study, $\eta$ can be the acoustic pressure $p^{\prime}$ or acoustic velocity $v^{\prime}$ at a given location in the experimental rig, or the heat release rate integrated over the entire combustion chamber, $\dot{q}^{\prime}$. Following [21], the function $f$ may be modeled as:

$f(\eta, \dot{\eta})=\dot{\eta}\left(\beta-\alpha-\kappa \eta^{2}\right)$

where $\alpha$ corresponds to the contribution of linear acoustic absorption in the volume and fluxes at the boundaries, meaning that it is positive. $\beta$ is the linear contribution of the feedback induced by the flame. It is positive when the flame drives the instability and negative when unsteady combustion damps acoustic fluctuations. The coefficient $\kappa$ accounts for the non-linearity of flame response to acoustics and controls the amplitude of the limit cycle reached when the system is linearly unstable. The growth/damping rate, $v$, of the system is defined as:

$v=\frac{\beta-\alpha}{2}$.

Without combustion, $\beta=0$, then $v=-\alpha / 2$, so that the system is always stable. In a reacting flow, if $\beta>\alpha$ then $v>0$, meaning that the driving contribution of the flame overcomes the linear acoustic losses and the system becomes linearly unstable. On the other hand, if $\beta<\alpha$ the system is linearly stable.

Eqs. (1) -3 provide the proper background for the extraction of the deterministic quantities $\omega_{0}$ and $v$ from experimental data. Four identifications methods are now presented: Harmonic Response (HR), Impulse Response (IR), Active Control (AC) and White Noise $(\mathrm{WN})$.

\subsection{Harmonic response method (HR)}

The harmonic response has been extensively used in the study of combustion instabilities for non-reacting [22] and reacting $[20,23]$ flows. However, this technique is limited to systems featuring negative growth rates, i.e. $v<0$. For a linearly stable system, the non-linear part of Eq. (2) can be neglected as long as perturbations to the equilibrium state are small so that Eq. (1) reduces to:

$\ddot{\eta}-2 v \dot{\eta}+\omega_{0}^{2} \eta=\xi$

Taking the power spectral density of Eq. (4) yields:

$\mathcal{S}_{\eta}=\frac{\mathcal{S}_{\xi}}{\left(\omega_{0}^{2}-\omega^{2}\right)^{2}+4 v^{2} \omega^{2}}$ 
where $\mathcal{S}_{\eta}$ (respectively $\mathcal{S}_{\xi}$ ) is the power spectral density of $\eta$ (respectively $\xi$ ). Eq. (5) indicates that the system has a maximum response at the angular frequency $\omega=\omega_{0} \sqrt{1-\left(v / \omega_{0}\right)^{2}}$ with a width at the half maximum of $2 v$. Consequently, the principle of the HR method is to determine $\omega_{0}$ and $v$ by applying an optimal fit of Eq. (5) to the power spectral density of experimentally measured $p^{\prime}, v^{\prime}$ or $\dot{q}^{\prime}$.

\subsection{Impulse response method (IR)}

For combustion application, the impulse response method has been less used $[20,24]$ than the HR method. Moreover, it is only suitable for linearly stable systems, i.e. when $v<0$. The system is pushed away from its steady state by a very short perturbation and it subsequently behaves as a damped harmonic oscillator, which obeys the homogeneous form of Eq. (1):

$\ddot{\eta}-2 v \dot{\eta}+\omega_{0}^{2} \eta=0$

Because non-linear terms have been neglected, Eq. (6) is only valid for small amplitudes. In the limit case where $\left(v / \omega_{0}\right)^{2}<<1$, which has been verified for all cases presented in this paper, the solution of Eq. (6) is:

$\eta=\eta_{0} e^{v t} \cos \left(\omega_{0} t+\phi\right)$

Thus, the principle of the IR method is to determine $\omega_{0}$ and $v$ by fitting Eq. (7) to the time traces of the flow variables $p^{\prime}, v^{\prime}$ or $\dot{q}^{\prime}$.

\subsection{Active control method (AC)}

Active control of combustion instabilities has been used in the combustion community for a while [25-29] and more recently [30]. It was first introduced in the 1980s on a Rijke tube [31], demonstrating that using a very small fraction of the system energy, the acoustic pressure amplitude can be reduced by several orders of magnitude. The theory behind active control of combustion instabilities is out of the scope of this study, here we simply use this technique with the intent to measuring $\omega_{0}$ and $v$.

Once a system with a positive growth rate $(\nu>0)$, is stabilized by an active control method, it is possible to stop the control and study the temporal evolution of the system in the linear regime. Although the growth rate is positive, the assumptions of Section 2.2 still hold so that the system follows Eq. (7).

The principle of the AC method is then the same as the IR method: recovering $\omega_{0}$ and $v$ by fitting Eq. (7) to the time traces of $p^{\prime}, v^{\prime}$ or $\dot{q}^{\prime}$. Care needs to be taken regarding the assumption of linearity of the flame response meaning that only small amplitudes should be considered.

\subsection{White noise method (WN)}

Stochastic white noise was used in $[21,32]$ to retrieve the deterministic parameters of a second-order dynamic system and in [13] to calculate the FTF of a swirl burner in a LES simulation. In [21], the forcing originated from turbulent fluctuations or from actuators excited by a signal generator. Unlike other methods, WN is adequate for both stable and unstable cases. However, as it is based on the processing of stochastic data, long temporal samples are needed to obtain accurate results.

When the system features a negative growth rate $(v<0)$, the assumption of Section 2.1 still hold. The difference between the HR and WN methods lies in the nature of the forcing, which is harmonic for the former and non-coherent stochastic white noise for the latter. The procedure for the determination of $\omega_{0}$ and $v$ is then the same as for the HR method: fitting Eq. (5) to the power spectral density of experimentally measured $p^{\prime}, v^{\prime}$ or $\dot{q}^{\prime}$.
Table 1

Summary of the different methods and the configuration to which they apply

\begin{tabular}{lll}
\hline & Model equation & Configuration \\
\hline $\mathrm{HR}$ & $\mathcal{S}_{\eta}(\omega)=\frac{\mathcal{S}_{\xi}}{\left(\omega_{0}^{2}-\omega^{2}\right)^{2}+4 \nu^{2} \omega^{2}}$ & Stable \\
$\mathrm{IR}$ & $\eta(t)=\eta_{0} e^{v t / 2} \cos \left(\omega_{0} t+\phi\right)$ & Stable \\
$\mathrm{AC}$ & $\eta(t)=\eta_{0} e^{\nu t / 2} \cos \left(\omega_{0} t+\phi\right)$ & Unstable \\
$\mathrm{WN}_{a}$ & $\mathcal{S}_{\eta}(\omega)=\frac{\mathcal{S}_{\xi}}{\left(\omega_{0}^{2}-\omega^{2}\right)^{2}+4 \nu^{2} \omega^{2}}$ & Stable \\
$\mathrm{WN}_{b}$ & $\mathcal{S}_{A^{\prime}}(\omega)=\frac{A_{0}^{0}}{\pi} \frac{c_{0}}{\omega^{2}+\left(2 v+c_{0}\right)^{2}}$ & Unstable \\
\hline
\end{tabular}

The case of a linearly unstable system featuring a positive growth rate $(v>0)$ is now considered. As lucidly explained in [21] the amplitude, $A$, of the limit cycle fluctuates around a mean value, $\bar{A}$, because of the stochastic perturbations from $\xi$. These fluctuations are denoted $A^{\prime}$ and follow the first-order differential equation:

$\dot{A}^{\prime}=-\left(2 v+c_{0}\right) A^{\prime}+\zeta$

where $c_{0}=\pi \mathcal{S}_{\xi} / 2 \omega_{0}^{2} A_{0}^{2}, A_{0}$ is the amplitude of the limit cycle without stochastic forcing ${ }^{1}$ and $\zeta$ is an uncorrelated white noise with an intensity related to that of $\xi$ through $\mathcal{S}_{\zeta}=\mathcal{S}_{\xi} / 2 \omega_{0}^{2}$. Taking the PSD of Eq. (8) yields:

$\mathcal{S}_{A^{\prime}}=\frac{A_{0}^{2}}{\pi} \frac{c_{0}}{\omega^{2}+\left(2 v+c_{0}\right)^{2}}$

The principle of the WN method for an unstable flame consists in fitting Eq. (9) to experimental data. As noted in [21] this method is valid only if the limit cycle is weakly perturbed by additive white noise, i.e. $v \gg c_{0}$.

The various methods proposed for the determination of the growth rate of combustion instabilities are summarized in Table 1. It should be pointed out that the methods described in Section 2.1 and Section 2.4 for stable systems assume that there is no linear modal interaction, i.e. the eigenfrequencies are not too close from each other. Otherwise, the responses related to two adjacent modes may overlap. In the present work, this is not a problem since the closest mode is several hundred Hertz away. However, in annular systems for example, the modal density is usually quite high, questioning the applicability of the methods.

\section{Experimental set-up}

The experiment is a slot burner [20,33] with a laminar premixed methane/air flame stabilized at the burner outlet (cf. Fig. 1). The four main components are: a mixing chamber, a plenum, a convergent nozzle and a rectangular-cross-section slot (width $w_{s}=$ $10 \mathrm{~mm}$ and length $l_{s}=100 \mathrm{~mm}$ ) with a height $h_{s}=70 \mathrm{~mm}$. The flow rates of air and methane are controlled and measured via individual mass flow meters (Bronkhorst F-201 AV-AAD-33-V). Reactants are injected at the bottom of the mixing chamber in a crossflow configuration to maximize mixing. The premixed flow is then laminarized in the plenum by an array of small glass balls and three honeycomb panels. Finally, it passes through the converging nozzle and the slot. The level of premixing is excellent as the flame shape is regular and steady in stable operating points. The temperature of the burner rim is controlled by four water cooled cylindrical passages. The water temperature in the upper channels can be set between 1 and $99{ }^{\circ} \mathrm{C}$, with a mass flow rate up to $1 \mathrm{~kg} / \mathrm{min}$. In the lower channels, water at ambient temperature flows at $5 \mathrm{~kg} / \mathrm{min}$. The purpose of this dual-channel cooling system is to be able to control $T_{S}$, while maintaining the lower part of the slot and the burner under ambient conditions.

\footnotetext{
${ }^{1}$ In the limit of small perturbations, one has $\bar{A} \approx A_{0}$.
} 


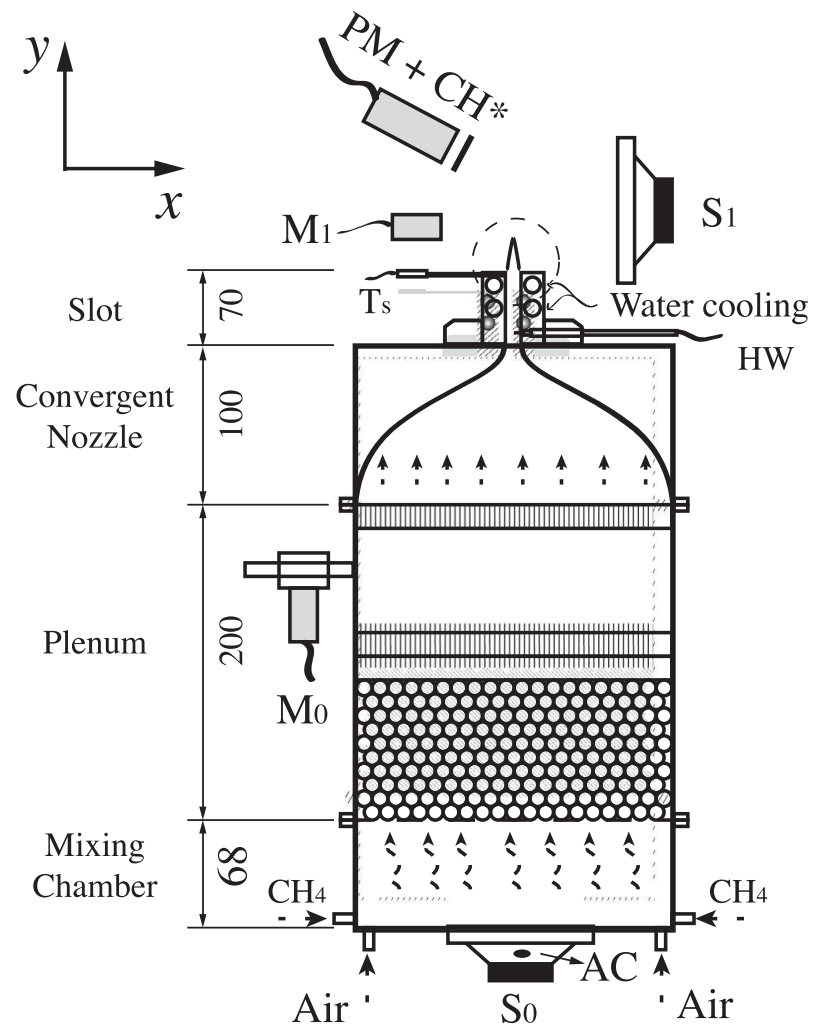

Fig. 1. Sketch of the burner: transverse cut and experimental diagnostics. $\mathrm{M}_{0}$ and $\mathrm{M}_{1}$ are $1 / 4^{\prime \prime}$ microphones. $\mathrm{PM}+\mathrm{CH}^{*}$ is a photomultiplier equipped with $\mathrm{CH}^{*}$ filter. HW corresponds to a hotwire. $T_{s}$ is K-type thermocouple. $S_{1}$ and $S_{2}$ are two loudspeakers. AC is an accelerometer.

\subsection{Diagnostics}

A K-type thermocouple is placed $1 \mathrm{~mm}$ below the burner outlet. It gives the temperature, $T_{s}$, of the material as close as possible to the flame base. A hot-wire probe (Dantec Dynamics, Mini CTA equipped with a 55P16 probe), labeled HW in Fig. 1, is used to measure the unsteady axial velocity $v(t)$, located $55 \mathrm{~mm}$ upstream of the slot outlet. A photomultiplier (Thorlabs, Bialkali PMT, PMM01), labeled PM in Fig. 1, measures the unsteady intensity, $I(t)$, of spontaneous emission of $\mathrm{CH}^{*}$ radicals. The PM is equipped with a narrow-band filter centered on a wavelength $\lambda=430 \mathrm{~nm}$ and is placed $400 \mathrm{~mm}$ away from the flame, aligned with the $z$ axis, facing the longitudinal axis of the flame, which is fully included in its field of view. It has been shown that for lean premixed flames, $I(t)$ is proportional to the heat release rate [34]. Two microphones, $\mathrm{M}_{0}$ and $\mathrm{M}_{1}$, (B\&K 1/4" Prepolarized Free-field 4954B) are used to record the acoustic pressure fluctuation, $p_{0}^{\prime}(t)$ and $p_{1}^{\prime}(t)$, respectively. $\mathrm{M}_{0}$ is placed in a waveguide connected to a pressure plughole in the middle of the plenum [35], while $\mathrm{M}_{1}$ is located $300 \mathrm{~mm}$ away from the burner. Two loudspeakers (Focal, ISN 100), one in the interior, $S_{0}$ and the other at the exterior of the burner, $S_{1}$, are used to generate acoustic waves prescribed by a signal generator (National Instruments, PCI-6052E). Moreover, an accelerometer (AllianTech, ultra miniature 3224A3 accelerometer) is placed on the membrane of the loudspeaker $S_{0}$ in order to monitor its displacement.

\section{Experimental results}

The four identification methods described in Section 2 are now applied to the burner of Fig. 1 in order to estimate the frequency, $\omega_{0}$ and growth/damping rate, $v$. This slot burner is operated close to its stability limit. This limit is controlled by the burner-rim tem-
Table 2

Summary of the operating points chosen for the evaluation of the characteristic parameters of the system. The identification methods applicable to each operation points are highlighted in grey.

\begin{tabular}{llllllll}
\hline Operating point & Name & $\Phi[-]$ & $T_{s}\left[{ }^{\circ} \mathrm{C}\right]$ & HR & IR & AC & WN \\
\hline Non Reacting & NR & 0.00 & 20 & N/A & N/A & N/A \\
Reacting Very Stable & RVS & 0.90 & 120 & N/A & N/A & N/A \\
Reacting Stable & RS & 0.85 & 120 & N/A & N/A & N/A \\
Reacting Slightly Unstable & RSU & 0.80 & 120 & & & N/A \\
Reacting Unstable & RU & 0.80 & 60 & & & N/A \\
Reacting Very Unstable & RVU & 0.80 & 20 & & & N/A & N/A \\
\hline
\end{tabular}
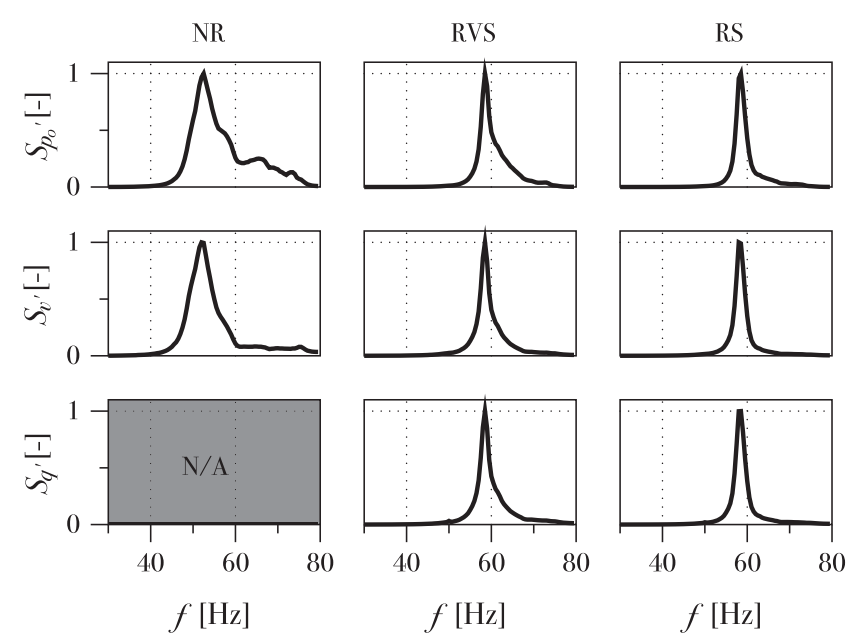

Fig. 2. Results for the HR method for the three stable operating points, NR (left) RVS (center) and RS (right). The rows correspond to the three different state variables: internal pressure $p_{0}^{\prime}$ (top row), velocity $v^{\prime}$ (middle row) and heat release rate $\dot{q}^{\prime}$ (bottom row).

perature, which can be used in a reliable and repeatable way to adjust the level of instability [20]. Changing the cooling-water temperature allows to cross the stability limit so that the accuracy of each identification method can be tested. Five different combinations of equivalence ratio, $\Phi$, and burner rim temperature, $T_{S}$, were chosen as operating points. The bulk velocity, $v_{b}=1.8 \mathrm{~ms}^{-1}$, and fresh gases temperature, $T_{g}=27{ }^{\circ} \mathrm{C}$, are kept constant. Table 2 presents the operating conditions: one non reacting and five reacting cases. Two stable ${ }^{2}$ and three unstable conditions are considered. The unstable points have different limit-cycle amplitudes of heat release rate fluctuations, which are $3 \%, 7 \%$ and $12 \%$ of the mean, for the Reacting Slightly Unstable (RSU), Reacting Unstable (RU) and Reacting Very Unstable (RVU) cases, respectively. Table 2 also shows, in grey, which identification method is applicable for each operating point.

\subsection{Harmonic response}

The HR method can be applied to the three stable cases: NR, RVS and RS. The external loudspeaker $S_{1}$ ( $c f$. Fig. 1) delivers an harmonic excitation $\xi=\Re\left(\xi_{0} e^{-i \omega t+\phi}\right)$ towards the flame. The fluctuations of the flow variables, were characterized for frequencies, between $f=30 \mathrm{~Hz}$ and $80 \mathrm{~Hz}$ by steps of $\Delta f=0.5 \mathrm{~Hz}$. The amplitude of the input signal is kept constant for all frequencies. The signal is $2 \mathrm{~s}$ long and the result, for each frequency, is the average of 4 samples.

Figure 2 shows the normalized power spectral density of pressure $\left(\mathcal{S}_{p_{0}^{\prime}}\right)$, velocity $\left(\mathcal{S}_{v^{\prime}}\right)$ and heat release rate $\left(\mathcal{S}_{\dot{q}^{\prime}}\right)$ fluctuations for the three cases.

\footnotetext{
${ }^{2}$ Heat release rate fluctuations are less than $1 \%$ of the mean during stable operation.
} 


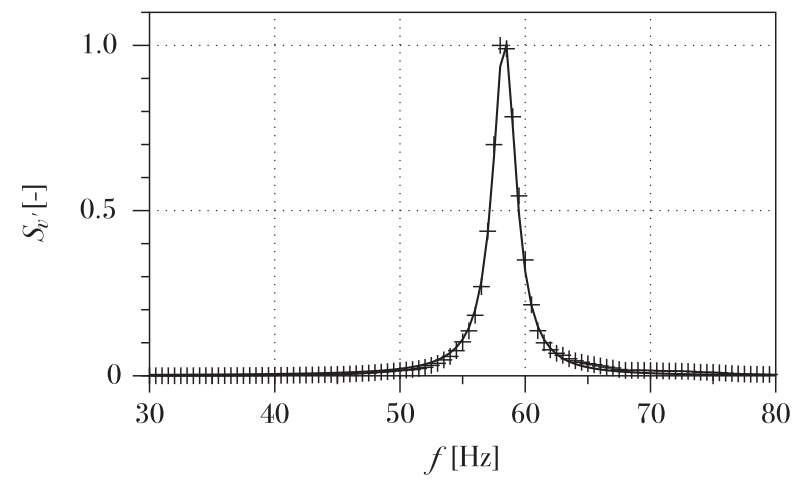

Fig. 3. PSD of the velocity signal, $\mathcal{S}_{v^{\prime}}$ : + RS operating point fit with Eq. (5).

Table 3

Results for the HR method applied to the stable cases, NR, RVS and RS.

\begin{tabular}{lllllllll}
\hline & $\mathrm{NR}$ & & & \multicolumn{2}{l}{$\mathrm{RVS}$} & & \multicolumn{2}{l}{$\mathrm{RS}$} \\
& $f_{0, n r}[\mathrm{~Hz}]$ & $\alpha\left[\mathrm{s}^{-1}\right]$ & & $f_{0}[\mathrm{~Hz}]$ & $v\left[\mathrm{~s}^{-1}\right]$ & & $f_{0}[\mathrm{~Hz}]$ & $v\left[\mathrm{~s}^{-1}\right]$ \\
\hline$p_{0}^{\prime}$ & 53.50 & -23.57 & & 58.87 & -10.55 & & 58.52 & -7.47 \\
$v^{\prime}$ & 52.35 & -17.86 & & 58.58 & -9.06 & & 58.36 & -7.09 \\
$\dot{q}^{\prime}$ & - & - & & 58.63 & -9.50 & & 58.39 & -7.38 \\
Mean & $\mathbf{5 2 . 9 9}$ & $-\mathbf{2 0 . 7 1}$ & & $\mathbf{5 8 . 6 9}$ & $-\mathbf{9 . 7 0}$ & & $\mathbf{5 8 . 4 3}$ & $-\mathbf{7 . 3 1}$ \\
std. & $\mathbf{0 . 8}$ & $\mathbf{4 . 0 4}$ & & $\mathbf{0 . 1 6}$ & $\mathbf{0 . 7 7}$ & & $\mathbf{0 . 0 8}$ & $\mathbf{0 . 2 0}$ \\
\hline
\end{tabular}

All variables exhibit a peak in the magnitude of the response, typical of a resonance, as expected from Eq. (5). The presence of the flame has a three consequences:

1. The peak shifts to the right meaning that unsteady combustion slightly increases $\omega_{0}$.

2. The width of the resonance peak decreases with combustion, indicating that the flame has a destabilizing effect on the system. However, its contribution is not sufficient to overcome linear acoustic losses so that the burner remains stable.

3. The absolute amplitude of the acoustic signal at the response frequency increases with combustion, which confirms item (2). The rms of pressure fluctuations for the NR, RVS and RS cases are 3.7 Pa, 9.7 Pa and 12.1 Pa, respectively.

It should also be pointed out that the PSD of pressure in the NR case is more noisy. No exact explanation for this is available at the moment. However, taking into account that the same excitation amplitude was used in non-reacting and reacting cases, the signal to noise ratio is lower in the NR case due to its smaller growth rate. Nevertheless, this does not elucidate why the velocity spectrum is less noisy than that of the pressure.

In order to illustrate the post-processing procedure, the PSD of velocity in the RS operating point is presented in Fig. 3, together with the corresponding fit from Eq. (5). For this specific case, $f_{0}=\omega_{0} / 2 \pi=58.36 \pm 0.016 \mathrm{~Hz}$ and $v=7.1 \pm 0.14 \mathrm{~s}^{-1}$, with a $95 \%$ confidence interval.

The results for the HR method are summarized in Table 3 and they quantify the qualitative observations obtained from Fig. 2. The peak in the spectrum of the response is shifted by $10 \%$ between non-reacting and reacting cases and it is almost equal for the RVS and RS cases. With the flame, $v$ increases but remains negative. The system is still stable but closer to the stability limit. Likewise, $|v|$ is larger for the RVS than RS case, which is consistent with the results of [36].

\subsection{Impulse response}

The IR method is now applied to the NR, RVS and RS operating points. A short impulse, $\delta$, is delivered by the loudspeaker $\mathrm{S}_{0}$ at
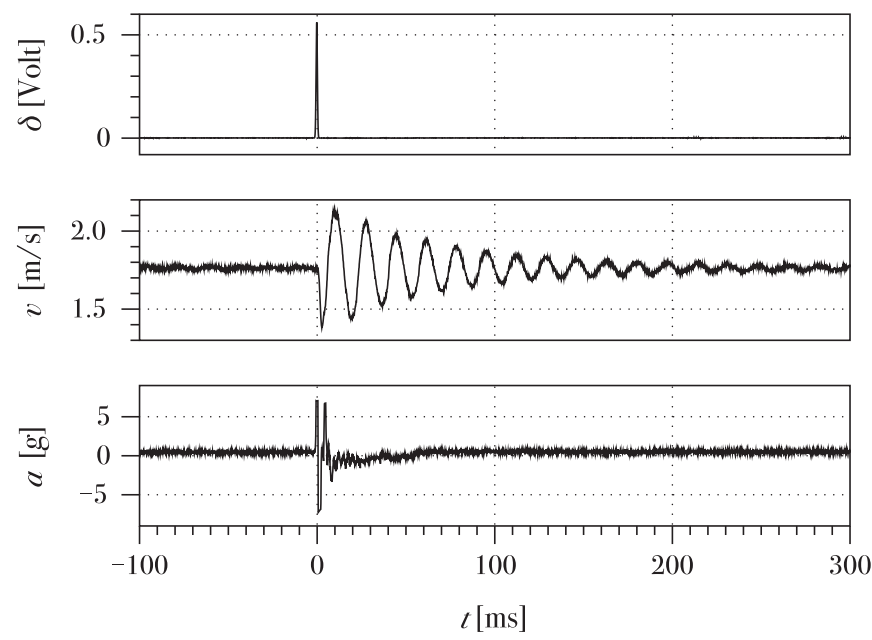

Fig. 4. Typical response to an impulse delivered by $S_{0}$ for the RVS case. Top: electrical impulse, $\delta$, sent to the loud speaker; Middle: velocity signal, $v$; Bottom: accelerometer signal, $a$.

the bottom of the plenum (cf. Fig. 1):

$\delta(t)=\frac{1}{A_{I R} \sqrt{\pi}} e^{-\left(t / \tau_{I R}\right)^{2}}$

where $A_{I R}=0.94 \mathrm{~V}$ is the amplitude of the electric signal sent to the amplifier and $\tau_{I R}=0.2 \mathrm{~ms}$. The time traces recorded for the RVS case are shown in Fig. 4. At $t<0$ the system is stable, then at $t=0$ the impulse is generated. The membrane of the loudspeaker experiences a strong acceleration and returns to equilibrium in less than $20 \mathrm{~ms}$. The flow velocity is also perturbed by the impulse and slowly returns to equilibrium, in about $400 \mathrm{~ms}$, with oscillations typical of an under-damped system. The fact that the loudspeaker membrane returns to equilibrium faster than the acoustic velocity is a good indication that fluctuations observed in the flow variables, correspond to the response of the burner, rather than residual forcing. The accuracy of this method is limited to high values of signal to noise ratio. Significant errors occur when the signal to noise ratio falls below 10 with respect to the initial amplitude [24]. In order to eliminate the high frequency noise seen in the velocity signal of Fig. 4, the impulse is repeated 400 times spaced of $10 \mathrm{~s}$ for each operating point. Finally, the IR is averaged over the 400 samples, increasing the signal to noise ratio from 11 to 31 .

The averaged time traces for $p_{0}^{\prime}, v^{\prime}$ and $\dot{q}^{\prime}$ are presented in Fig. 5, for the three linearly stable cases NR, RVS and RS. While velocity shows a monotonous decay, pressure fluctuations initially increase after the impulse for about two cycles. Given the amplitude of the excitation, the initial heat release rate fluctuations are fairly non-linear, which is to be expected [22]. Like for the HR method (cf. Fig. 2), the pressure signal for the non-reacting case is not as clean as for the other operating conditions.

For the fit to Eq. (7), the experimental data is restricted between $80 \%$ and $10 \%$ of its peak amplitude. A typical example of this fit for the RVS case is presented in Fig. 6.

Table 4 summarizes the results of the IR method, which are consistent with the HR results of Table 3.

\subsection{Active control}

The AC method can in principle be applied to all unstable operating conditions. However, because the amplitude of the fluctuations are very small in the RSU case, the active control does not bring significant reduction for this regime. It is therefore only applied to the RU and RVU cases. The active control technique used in this study is a fixed-coefficients closed-loop controller [26]. 
NR
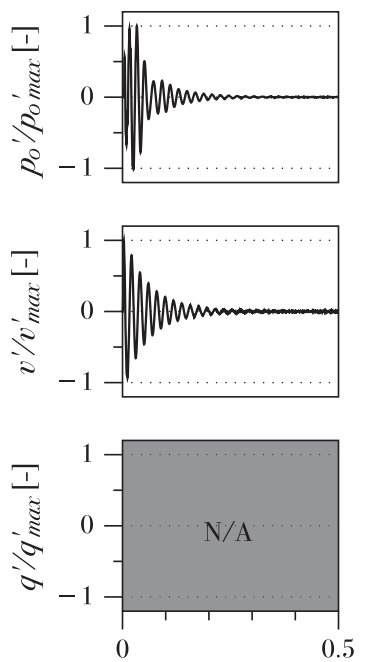

$t[\mathrm{~s}]$
RVS
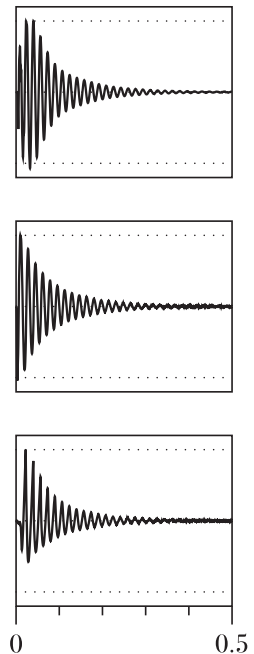

$t[\mathrm{~s}]$
RS
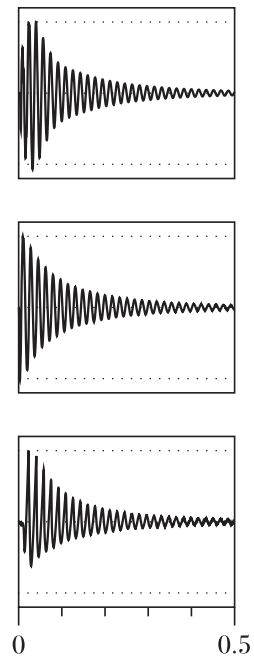

$t[\mathrm{~s}]$
Fig. 5. Results for the impulse response method for the three stable operating points (NR, RVS and RS) and the three measured variables (pressure $p_{0}^{\prime}$, velocity $v^{\prime}$ and heat release rate $\dot{q}^{\prime}$. All signals are normalized by their maximum value.

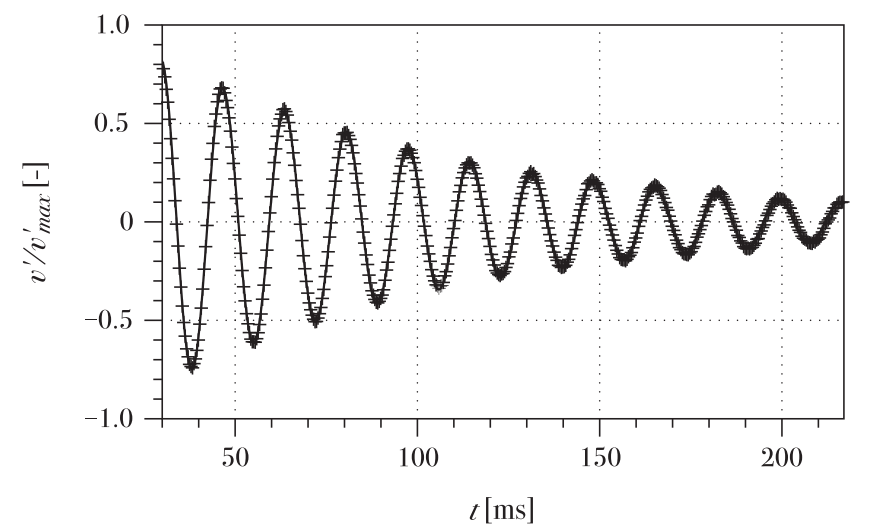

Fig. 6. Velocity signal for the IR method: + RVS operating point, __ fit with Eq. (7).

Table 4

Results for the IR tests applied to the stable cases, NR, RVS and RS.

\begin{tabular}{|c|c|c|c|c|c|c|}
\hline & \multicolumn{2}{|l|}{ NR } & \multicolumn{2}{|l|}{ RVS } & \multicolumn{2}{|l|}{ RS } \\
\hline & $f_{0, n r}[\mathrm{~Hz}]$ & $\alpha\left[\mathrm{s}^{-1}\right]$ & $f_{0}[\mathrm{~Hz}]$ & $v\left[\mathrm{~s}^{-1}\right]$ & $f_{0}[\mathrm{~Hz}]$ & $v\left[\mathrm{~s}^{-1}\right]$ \\
\hline$p_{0}^{\prime}$ & 51.60 & -15.20 & 58.67 & -11.53 & 58.34 & -6.67 \\
\hline$v^{\prime}$ & 51.68 & -15.61 & 59.01 & -11.50 & 58.35 & -6.64 \\
\hline$\dot{q}^{\prime}$ & - & - & 58.91 & -11.41 & 58.38 & -6.63 \\
\hline Mean & 51.64 & -15.41 & 58.90 & -11.48 & 58.44 & -6.65 \\
\hline std. & 0.08 & 0.29 & 0.12 & 0.06 & 0.02 & 0.02 \\
\hline
\end{tabular}

The signal from the plenum microphone, $\mathrm{M}_{0}$ is phase delayed, amplified and sent to the speaker $S_{0}$ mounted on the bottom of the plenum (cf. Fig. 1). The gain and phase lag of this controller are constant and identical for the RU and RVU cases.

Figure 7 shows the spectra of the velocity fluctuations for the RVU case, with and without active control. When activated, AC reduces the amplitude of the fundamental frequency by almost $50 \mathrm{~dB}$.

The procedure for the AC measurements is based on that of [26] and is as follows: the controller is turned on and the system is kept stable for a few seconds; the control is then turned off

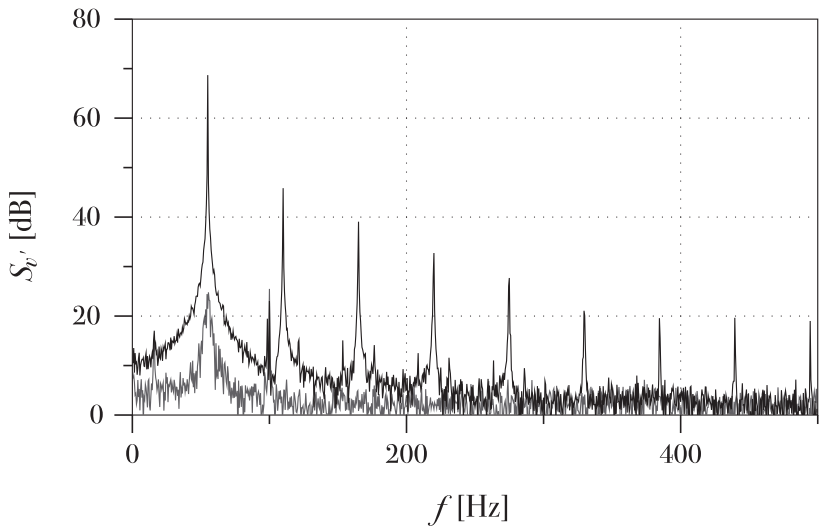

Fig. 7. PSD of velocity fluctuations: — with active control, $\_$without active control.

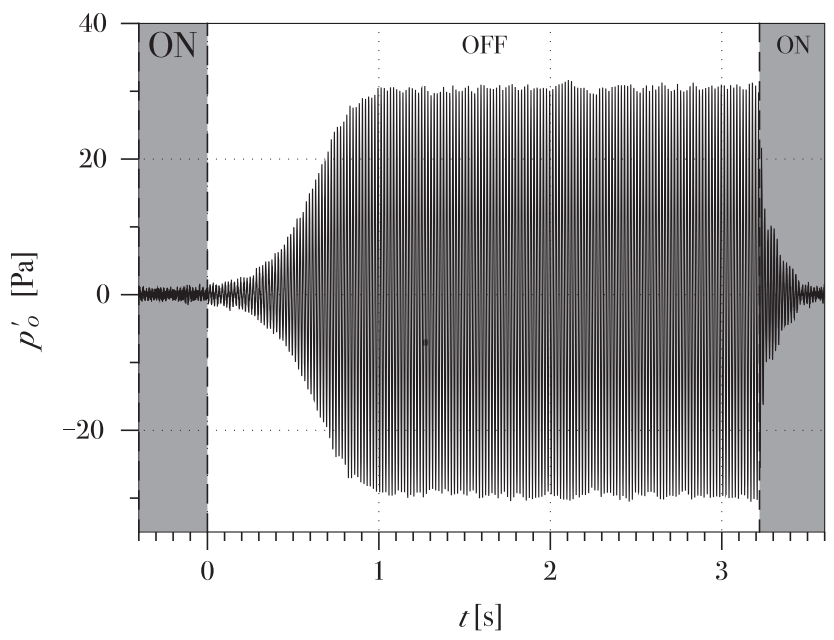

Fig. 8. Internal acoustic pressure, $p_{0}^{\prime}(t)$, for a RVU cycle of operation where the active control is switched OFF and ON.

Table 5

Results of the AC method for the RU and RVU operating points.

\begin{tabular}{llllll}
\hline & $\mathrm{RU}$ & & \multicolumn{2}{l}{$\mathrm{RVU}$} \\
\cline { 2 - 3 } \cline { 5 - 6 } & $f_{0}[\mathrm{~Hz}]$ & $v\left[\mathrm{~s}^{-1}\right]$ & & $f_{0}[\mathrm{~Hz}]$ & $v\left[\mathrm{~s}^{-1}\right]$ \\
\hline$p_{0}^{\prime}$ & 56.02 & 1.80 & 55.00 & 4.91 \\
$v^{\prime}$ & 56.01 & 1.84 & 54.99 & 4.93 \\
$\dot{q}^{\prime}$ & 56.01 & 1.61 & 55.00 & 4.38 \\
Mean & $\mathbf{5 6 . 0 1}$ & $\mathbf{1 . 7 5}$ & $\mathbf{5 5 . 0 0}$ & $\mathbf{4 . 7 4}$ \\
std. & $\mathbf{0 . 0 0}$ & $\mathbf{0 . 1 2}$ & $\mathbf{0 . 0 0}$ & $\mathbf{0 . 3 1}$ \\
\hline
\end{tabular}

at $t=0$ and the instability grows. A typical time trace of plenum pressure fluctuations, $p_{0}^{\prime}$ is shown in Fig. 8.

This procedure is repeated 40 times and the measurements are phase averaged in order to reduce noise. Figure 9 shows the corresponding traces for RU and RVU, restricted to the interval where the amplitude is between $20 \%$ and $60 \%$ of the limit cycle, which is considered for post-processing. It is obvious that the RVU case is the most unstable as it takes less cycles to reach the upper bound.

The quantitative results of the AC method are summarized in Table 5. The growth rate is larger for the RVU condition, as expected from Fig. 9. Results also show very little dispersion regardless of the variable used for the analysis.

\subsection{White noise}

For the WN method, the stochastic non-coherent noise is imposed by the plenum loudspeaker $S_{0}$ (see Fig. 1 ). The amplitude of 
$\mathrm{RU}$
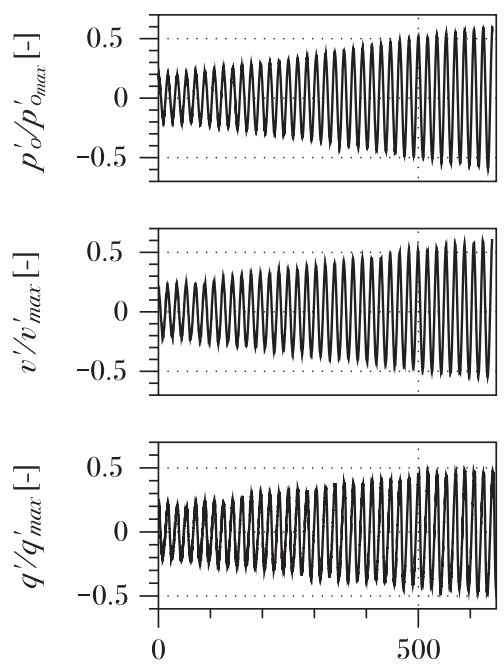

$t[\mathrm{~ms}]$
RVU
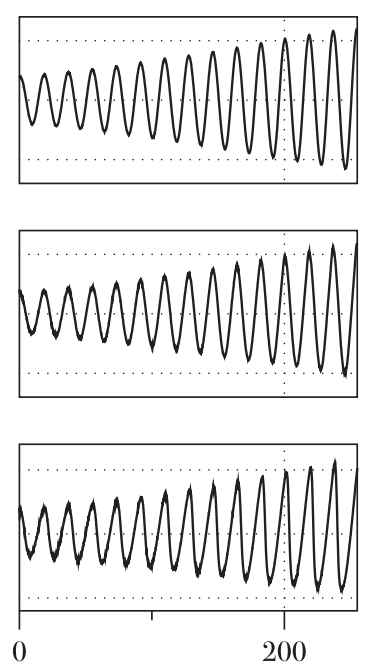

$\iota[\mathrm{ms}]$

Fig. 9. Averaged time traces of the AC test for RU and RVU conditions for the three flow variables, $p_{0}^{\prime}, v^{\prime}$ and $\dot{q}^{\prime}$.
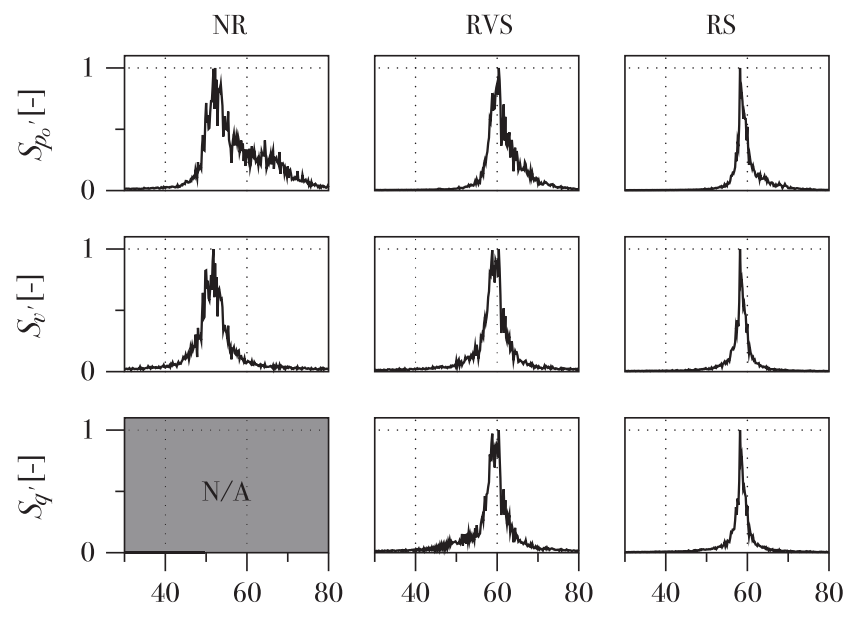

$f[\mathrm{~Hz}]$

$f[\mathrm{~Hz}]$

$f[\mathrm{~Hz}]$

Fig. 10. Power spectral density obtained with the WN method for the stable operating points, NR, RVS and RS.

the additive white Gaussian noise was chosen so that, in the case of a system with positive growth rate, $v$ is at least one order of magnitude larger than the amplitude of the normalized stochastic forcing level, $c_{0}$, as required for the analysis (cf. Section 2.4). This amplitude was kept constant for all stable and unstable cases. The processed signals are $100 \mathrm{~s}$ long and the acquisitions are repeated ten times for each operating point, this is equivalent to having signals containing approximately 60,000 cycles for unstable cases.

\subsubsection{Negative growth rate}

When the system is linearly stable, it is possible to extract the damping rate by fitting the power spectral density of the flow variables signals with the second order model given in Eq. (5). Each $100 \mathrm{~s}$ long trace is split in 20 equal parts for which the PSD is calculated. The resulting 200 PSDs are averaged to lower stochastic noise and the results of this procedure are shown in Fig. 10 for the three linearly stable cases NR, RVS and RS. The PSDs are very similar to the results of the HR method ( $c f$. Fig. 2) except that they are not as smooth. In order to illustrate the post processing procedure,

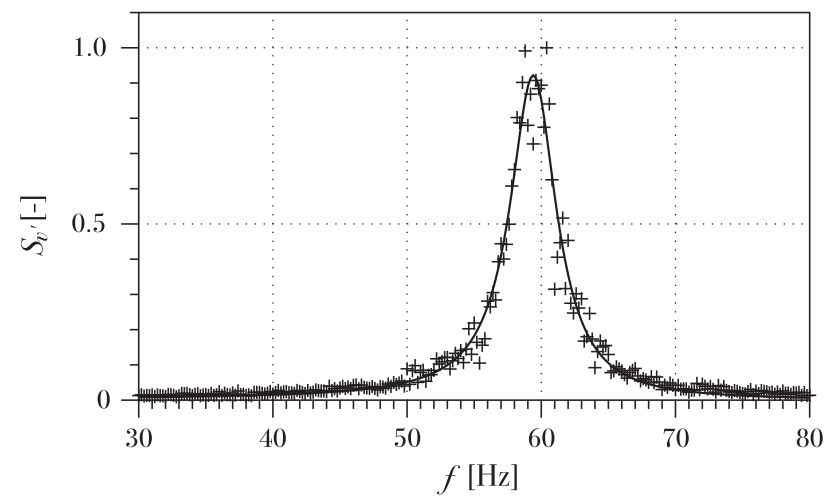

Fig. 11. PSD of velocity fluctuations with the WN method: + RVS operating point, fit with Eq. (5).

Table 6

Results of the WN method for the stable operating points: NR, RVS and RS.

\begin{tabular}{|c|c|c|c|c|c|c|}
\hline & \multicolumn{2}{|l|}{ NR } & \multicolumn{2}{|l|}{ RVS } & \multicolumn{2}{|l|}{ RS } \\
\hline & $f_{0, n r}[\mathrm{~Hz}]$ & $\alpha\left[\mathrm{s}^{-1}\right]$ & $f_{0}[\mathrm{~Hz}]$ & $v\left[\mathrm{~s}^{-1}\right]$ & $f_{0}[\mathrm{~Hz}]$ & $v\left[\mathrm{~s}^{-1}\right]$ \\
\hline$p_{0}^{\prime}$ & 53.81 & -27.12 & 60.33 & -14.81 & 58.80 & -7.91 \\
\hline$v^{\prime}$ & 51.83 & -17.34 & 59.48 & -13.23 & 58.56 & -7.19 \\
\hline$\dot{q}^{\prime}$ & - & - & 59.50 & -13.48 & 58.53 & -6.98 \\
\hline Mean & 52.82 & -22.23 & 59.77 & -13.84 & 58.63 & -7.63 \\
\hline std. & 1.40 & 6.92 & 0.49 & 0.85 & 0.15 & 0.49 \\
\hline
\end{tabular}

Fig. 11 shows the fit with Eq. (5) of the acoustic velocity spectrum for the RVS case.

The quantitative results of the WN method for the cases with negative growth rates are summarized in Table 6. These results are consistent with that of the HR methods ( $c f$. Table 3 ): the prediction of the frequency are within $1 \mathrm{~Hz}$ but the damping is systematically overestimated by the WN method, especially for the RVS case where it is $50 \%$ larger.

\subsubsection{Positive growth rate}

For the linearly unstable conditions (RSU, RU and RVU), the damping rate of the system is obtained with the WN method [21] by fitting the PSD of limit-cycle amplitude variations with Eq. (9). Similar to the linearly stable cases analyzed in Section 4.4.1, each $100 \mathrm{~s}$ trace is split in 5 equal parts, then the PSD of the magnitude of the analytic signal (i.e. the original signal $+\mathrm{i}$ times its Hilbert transform) is calculated for each interval. The resulting 50 PSDs are averaged, which reduces the high frequency noise by $10 \mathrm{~dB}$ and are presented in Fig. 12 for the for the three linearly unstable operating points. Qualitatively, Fig. 12 suggests that the cut-off frequency in the PSD of the limit-cycle amplitude increases from the RSU to the RU and RVU cases. Using Eq. (9), this indicates that the growth rate increases. The sharp peak around $8 \mathrm{~Hz}$ in the spectra of heat release rate corresponds to the flickering of the flame due to buoyancy. This perturbation is restricted to the burnt gases and therefore not measured in the pressure and velocity signals.

The post processing procedure is illustrated in Fig. 13, showing how the experimental PSD of the velocity signal for RSU is fit to Eq. (9).

Finally, the results of the $\mathrm{WN}$ method applied to the linearly unstable cases are summarized in Table 7. Comparing with the AC method presented in Table 5, the predictions of $\omega_{0}$ are virtually identical. The growth rates determinations are similar within a $15 \%$ range. 


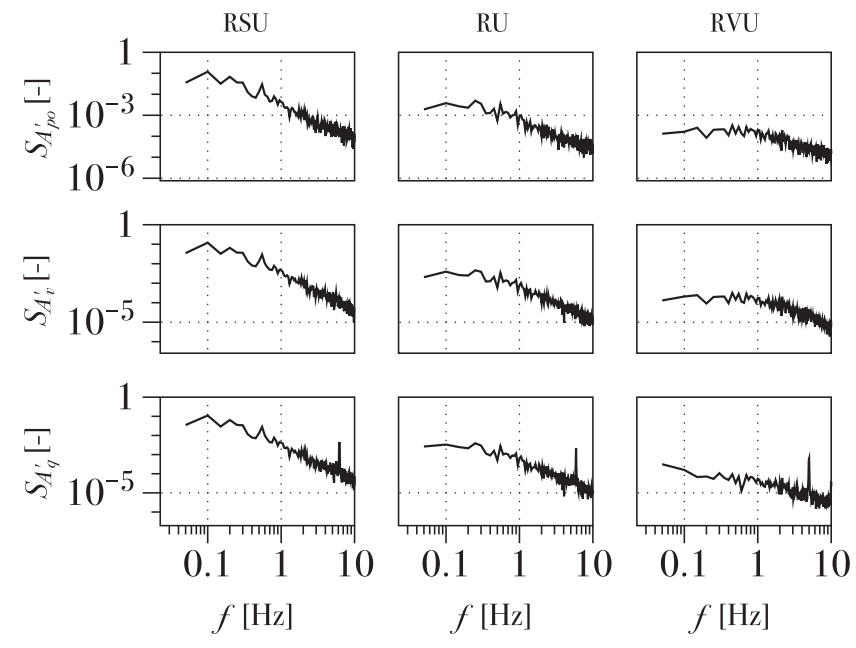

Fig. 12. PSD of the limit-cycle amplitude variations obtained with the WN method for the unstable operating points: RSU, RU and RVU.

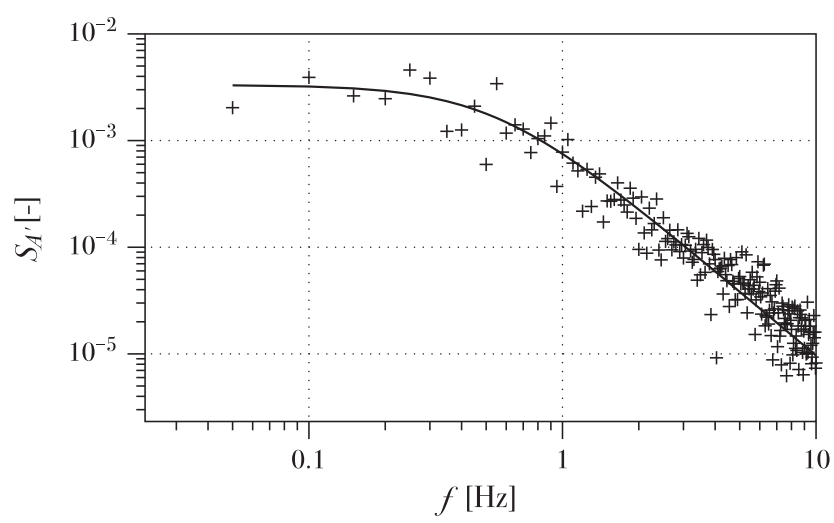

Fig. 13. Spectrum of limit-cycle amplitude variations for the velocity: + RVU operating point, fit with Eq. (9).

Table 7

Results of the WN method for the linearly unstable operating points: RSU, RU and RVU.

\begin{tabular}{|c|c|c|c|c|c|c|}
\hline & \multicolumn{2}{|l|}{ RSU } & \multicolumn{2}{|l|}{ RU } & \multicolumn{2}{|l|}{ RVU } \\
\hline & $f_{0}[\mathrm{~Hz}]$ & $v\left[\mathrm{~s}^{-1}\right]$ & $f_{0}[\mathrm{~Hz}]$ & $v\left[\mathrm{~s}^{-1}\right]$ & $f_{0}[\mathrm{~Hz}]$ & $v\left[\mathrm{~s}^{-1}\right]$ \\
\hline$p_{0}^{\prime}$ & 56.22 & 0.50 & 55.94 & 1.70 & 54.97 & 5.62 \\
\hline$v^{\prime}$ & 56.22 & 0.50 & 55.94 & 1.63 & 54.97 & 5.21 \\
\hline$\dot{q}^{\prime}$ & 56.22 & 0.55 & 55.94 & 1.46 & 54.97 & 5.22 \\
\hline Mean & 56.22 & 0.51 & 55.94 & 1.60 & 54.97 & 5.35 \\
\hline std. & 0.00 & 0.03 & 0.00 & 0.12 & 0.00 & 0.23 \\
\hline
\end{tabular}

\subsection{Summary}

The measurements of $f_{0}$ and $v$ obtained with the four techniques on the five operating points are summarized in Fig. 14, where each symbol corresponds to the mean value of all three flow variables for each operating point. For the NR case, because the pressure PSD are noisy, the evaluation with the HR and WN methods were discarded. All identification methods show consistent results for the resonance frequency, with a dispersion usually smaller than $1 \mathrm{~Hz}$. The growth / damping rates predictions are also surprisingly gathered. The largest dispersion between identification methods is found for the RVS case but no specific reason for this larger scatter is foreseen.
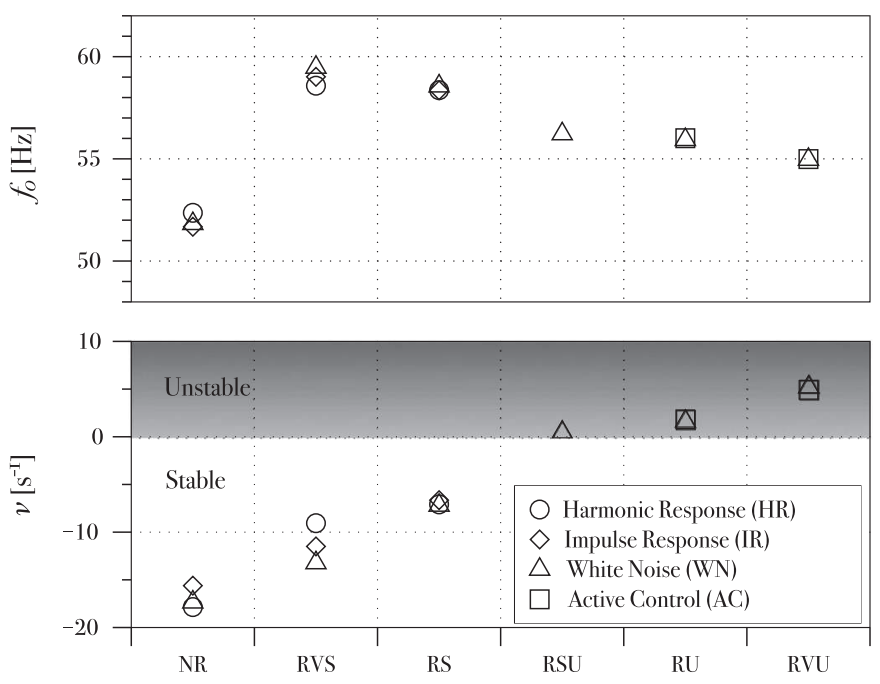

Fig. 14. Summary of all measurements for the determination of the frequency and growth rate of the first eigenmode of the slot burner.

\section{Validation}

At this point it is interesting to try and predict the stability map of Fig. 14. For this purpose, a low-order model of the present slot burner is now given, based on previous studies [22,35,37]. Because the combustion instability is here locked on the Helmholtz mode of the plenum, one can derive an analytical model valid for this specific mode. For harmonic velocity perturbations, $v^{\prime}=\tilde{v} e^{-i \omega t}$, the system obeys a second-order equation for the pulsation $\omega$, which may be written in the form $[20,36]$ :

$\left[1+\mathcal{N} e^{i \omega \tau}\right] \omega^{2}+2 i \alpha \omega-\omega_{0, n r}^{2}=0$

where $\omega_{0, n r}$ is the resonance frequency and $\alpha$ the damping rate of the system, both under non-reacting conditions. The fact that $\omega_{0, n r}$ and $\alpha$ correspond to non-reacting conditions stems from the derivation of the model [35-37]. The influence of the flame is modeled by an interaction index, $\mathcal{N}$, and a time delay, $\tau$, which are linked to the Flame Transfer Function (FTF). The FTF, $\mathcal{F}(\omega)$, is a complex number measuring the response of the flame to acoustics, and is expressed as the ratio of the relative heat release rate fluctuations, $\dot{q}^{\prime} / \bar{q}$, to the incoming velocity fluctuations, $v^{\prime} / \bar{v}$ :

$\mathcal{F}(\omega)=\frac{\dot{q}^{\prime} / \bar{q}}{v^{\prime} / \bar{v}}=\mathcal{G}(\omega) e^{i \varphi}$

where $\mathcal{G}$ is the gain of the FTF and $\varphi$ its phase, which is linked to the time delay, $\tau$, of the flame through $\varphi=\omega \tau$. Then, the interaction index, $\mathcal{N}$, is defined as:

$\mathcal{N}=\mathcal{C G}(\omega)$

where $\mathcal{C}$ is a factor accounting for sound radiation from the flame, depending on the burner geometry and the operating conditions. Following the work of Price et al. [34]:

$\mathcal{C}=\frac{1}{4 \pi} \frac{S_{s}}{h} \frac{E-1}{r}$

where $S_{s}=10^{-3} \mathrm{~m}^{2}$ is the slot cross section, $h=0.106 \mathrm{~m}$ the effective height of the $\operatorname{slot}^{3}$ and $E$ is the ratio of the fresh to the burnt-gases density. $E$ changes because the equivalence ratio is not the same for all cases. It is computed by an equilibrium calculation with the Cantera software. The distance between the noise source

${ }^{3}$ Two corrections must be applied to $h$ in order to account for the converging section upstream of the slot and the classical end-correction at the exit [36]. 
Table 8

Combustion noise parameters for the various operating conditions.

\begin{tabular}{llll}
\hline Test & $E[-]$ & $r[\mathrm{~mm}]$ & $\mathcal{C}[-]$ \\
\hline RVS & 7.10 & 24.35 & 0.19 \\
RS & 6.89 & 26.33 & 0.17 \\
RUS & 6.65 & 29.04 & 0.15 \\
RU & & & \\
RVU & & & \\
\hline
\end{tabular}
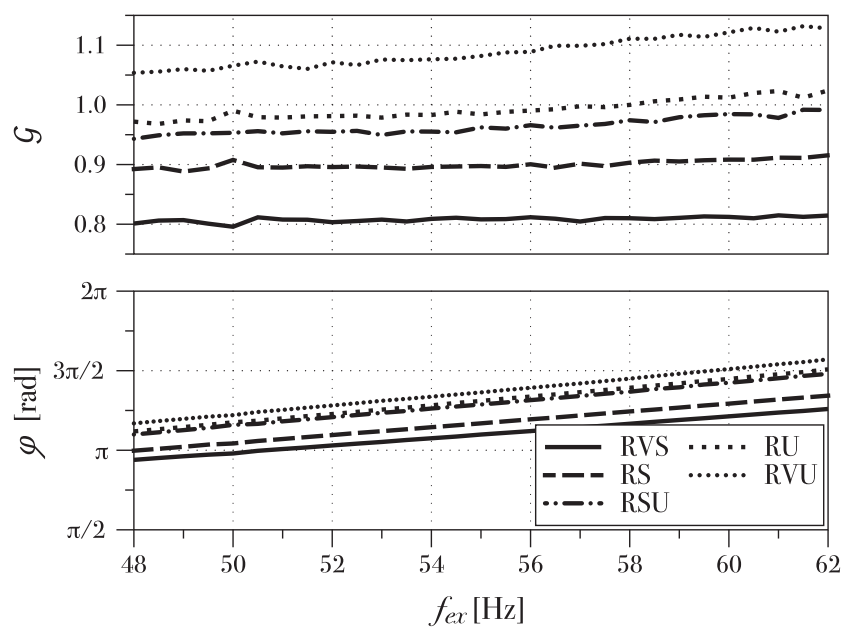

Fig. 15. FTF of the five reacting cases of Table 2. Gain, $\mathcal{G}$ (top) and phase $\varphi$ (bottom).

and the burner outlet is denoted $r$ and it is obtained from direct visualization as the location where the flame pinches [22]. The numerical values of $E, r$ and $\mathcal{C}$ and are recalled in Table 8 .

The stability of the system is determined by the complex roots, $\omega=\omega_{0}+i v$, of Eq. (11), which can be solved once the values of $\mathcal{N}, \tau, \omega_{0, n r}$ and $\alpha$ are known. This is the classical paradigm of stability map prediction with an acoustic solver: one must know $a$ priori the response of the flame and the acoustic damping rate of the setup. The requirement to know $\omega_{0, n r}$ is specific to the present model, which is valid for a flame locked on a Helmholtz mode. A more generic methodology, using for example a Helmholtz solver does not require the a priori knowledge of the eigenmodes. Using the results of Section 4 in the NR case, the values $f_{0, n r}=52.50 \mathrm{~Hz}$ and $\alpha=16.94 \mathrm{~s}^{-1}$ are used.

Finally, the FTF are obtained by the classical procedure of sending a small amplitude harmonic signal through the speaker $S_{0}$. The flame must be stable in order to measure the FTF and as explained in [36], a simple way to stabilize this setup is to increase the height of the slot. This modification does not alter the flame but shifts down the frequency of the Helmholtz mode. For the measurement of the FTF in the RSU, RU and RVU conditions, the height is increased to $150 \mathrm{~mm}$, resulting in stable combustion. It was checked for the stable operating points that the FTFs measured with a $150 \mathrm{~mm}$ slot and $70 \mathrm{~mm}$ slot are identical. Only the frequency range $[48,62] \mathrm{Hz}$ is needed for this study. Heat release rate and velocity fluctuations are recorded simultaneously by the photomultiplier and the hot-wire probe, respectively ( $c f$. Fig. 1). The level of rms velocity fluctuation is kept constant at $10 \%$ of the bulk velocity $\left(v_{b}=1.8 \mathrm{~m} / \mathrm{s}\right)$ for all frequencies. Figure 15 shows the gain and the phase of the FTF for the five reacting operating points, RVS, $\mathrm{RS}, \mathrm{RSU}, \mathrm{RU}, \mathrm{RVU}$. Because in the range of interest both the gain and the phase of the FTF vary linearly with $\omega$, for the numerical resolution of Eq. (11), they were interpolated with linear functions. It should be pointed out that, for all operating points, the phase of the FTF is between $[\pi, 2 \pi]$ at the frequency of the eigenmode,
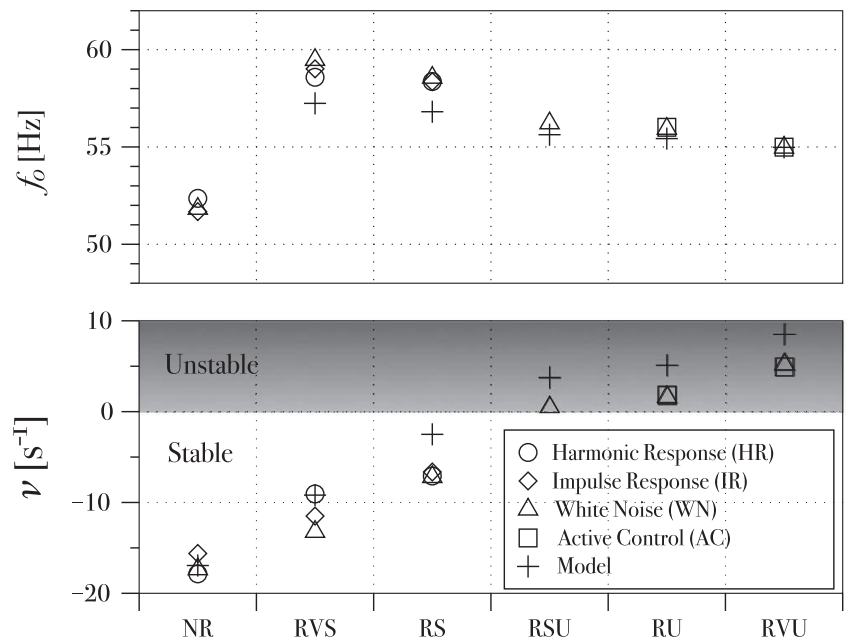

Fig. 16. Validation of Eq. (11) for the prediction of the frequency, $f_{0}$ and growth rate, $v$ of the eigenmode of the slot burner.

i.e. $[57,59] \mathrm{Hz}$. Thus, the necessary condition for an instability to develop, resulting from the Rayleigh criterion is fulfilled [22]. Nevertheless, only RSU RU RVS are unstable. The reason is that this condition is necessary but no sufficient: in order to trigger an instability the gain of the FTF must be large enough to overcome the various acoustic losses, which is not the case for the RVS an RS conditions.

The solutions of Eq. (11) are presented in Fig. 16. It is clear that the predictions of Eq. (11) closely follow the experimental data and always recover the proper stability of the eigenmode. While the frequencies typically match by less than $5 \%$, the growth rates are systematically overestimated by a few $\mathrm{Hz}$ for the reacting cases.

\section{Conclusion}

Four methods were presented for the experimental evaluation of the growth (or damping) rate associated with an acoustic eigenmode. The objective is the detailed analysis of combustion instabilities, either for the mitigation of unstable modes, or the assessment of the distance to the stability limit for a stable mode. These methods were tested on five operating points of a laminar slot burner: two stable and three unstable. The evaluation of the frequency and growth rate were consistent between the methods, giving confidence for their application.

Then a low-order model of the slot burner was derived for the prediction of its stability. The model was fed by Flame Transfer Functions obtained experimentally and its solutions were compared to the experiment. Both the frequency and the growth rate of the eigenmode were predicted with good accuracy for stable and unstable operating conditions. These results give a clear indication that the overall methodology of feeding low-order models or acoustic solvers by FTF is sound and accurate, even close to the stability limit.

It is suggested that these methods be used more systematically on laboratory and industrial burners because they provide the distance to the stability limit, which is very useful for the assessment of the robustness of a given design. Nevertheless, not all methods are suitable for all systems and some practical limitations should be discussed. For example, installing actuators such as loudspeakers inside combustion chambers is not always possible, especially on industrial burners with compact geometries. In such situation, if the flow is turbulent, the WN method presented in Section 2.4 is a good option. Also, the $\mathrm{HR}$ and $\mathrm{WN}_{a}$ methods assume that there is no linear modal interaction, that is, the eigenfrequencies need 
to be sufficiently far from each other. This may limit their use in systems where the modal density is high. In these cases the IR, AC or $\mathrm{WN}_{b}$ methods may be tried.

\section{Acknowledgments}

The research leading to these results has received funding from the European Research Council under the European Union's Seventh Framework Programme (FP/2007-2013) / ERC Grant Agreement ERC-AdG 319067-INTECOCIS.

\section{References}

[1] T.C. Lieuwen, Unsteady combustor physics, Cambridge University Press, 2012.

[2] F. Culick, Unsteady motions in combustion chambers for propulsion systems, NATO/RTO-AG-AVT-039, 2006.

[3] L. Boyer, J. Quinard, On the dynamics of anchored flames, Combust. Flame 82 (1) (1990) 51-65

[4] T. Schuller, D. Durox, S. Candel, Dynamics of and noise radiated by a perturbed impinging premixed jet flame, Combust. Flame 128 (1-2) (2002) 88-110.

[5] H.Y. Wang, C.K. Law, T. Lieuwen, Linear response of stretch-affected premixed flames to flow oscillations, Combust. Flame 156 (4) (2009) 889-895.

[6] R.S. Blumenthal, P. Subramanian, R. Sujith, W. Polifke, Novel perspectives on the dynamics of premixed flames, Combust. Flame 160 (7) (2013) 1215 1224 .

[7] T. Schuller, D. Durox, S. Candel, A unified model for the prediction of lamina flame transfer functions comparisons between conical and V-flame dynamics, Combust. Flame 134 (1-2) (2003) 21-34.

[8] A. Cuquel, D. Durox, T. Schuller, Impact of flame base dynamics on the nonlinear frequency response of conical flames, Comptes Rendus Mécanique 34 (1-2) (2013) 171-180.

[9] K. Kim, J. Lee, B. Quay, D. Santavicca, Response of partially premixed flames to acoustic velocity and equivalence ratio perturbations, Combust. Flame 157 (9) (2010) 1731-1744.

[10] D. Durox, J.P. Moeck, J.-F. Bourgouin, P. Morenton, M. Viallon, T. Schuller, S. Candel, Flame dynamics of a variable swirl number system and instability control, Combust. Flame 160 (9) (2013) 1729-1742.

[11] B. Ćosić, S. Terhaar, J.P. Moeck, C.O. Paschereit, Response of a swirl-stabilized flame to simultaneous perturbations in equivalence ratio and velocity at high oscillation amplitudes, Combust. Flame 162 (2014) 1046-1062.

[12] A. Giauque, L. Selle, L. Gicquel, T. Poinsot, H. Buechner, P. Kaufmann, W. Krebs, System identification of a large-scale swirled partially premixed combustor using LES and measurements, J. Turbul. 6 (February 2012) (2005) N21.

[13] L. Chong, T. Komarek, R. Kaess, S. Föller, W. Polifke, Identification of flame transfer functions from LES of a premixed swirl burner, Proceedings of the ASME Turbo Expo 2010 Power Land, Sea Air, ASME, Glasgow (2010).

[14] X. Han, J. Li, A.S. Morgans, Prediction of combustion instability limit cycle oscillations by combining flame describing function simulations with a thermoacoustic network model, Combust. Flame 162 (10) (2015) 1-16.

[15] P. Wolf, G. Staffelbach, LY. Gicquel, J-D. Müller, T. Poinsot, Acoustic and large Eddy simulation studies of azimuthal modes in annular combustion chambers, Combust. Flame 159 (11) (2012) 3398-3413.

[16] L. Selle, R. Blouquin, M. Théron, L.-H. Dorey, M. Schmid, W. Anderson, Prediction and analysis of combustion instabilities in a model rocket engine, J. Propuls. Power 30 (4) (2014) 978-990.
[17] N. Noiray, D. Durox, T. Schuller, S. Candel, A unified framework for nonlinear combustion instability analysis based on the flame describing function, J. Fluid Mech. 615 (2008) 139.

[18] J. Pieringer, T. Sattelmayer, F. Fassl, Simulation of combustion instabilities in liquid rocket engines with acoustic perturbation equations, J. Propuls. Power 25 (5) (2009) 1020-1031.

[19] C.F. Silva, F. Nicoud, T. Schuller, D. Durox, S. Candel, Combining a Helmholtz solver with the flame describing function to assess combustion instability in a premixed swirled combustor, Combust. Flame 160 (9) (2013) 1743-1754.

[20] D. Mejia, L. Selle, R. Bazile, T. Poinsot, Wall-temperature effects on flame response to acoustic oscillations, Proc. Combust. Inst. 35 (3) (2015) 3201-3208.

[21] N. Noiray, B. Schuermans, Deterministic quantities characterizing noise driven Hopf bifurcations in gas turbine combustors, Int. J. Non. Linear. Mech. 50 (2013) 152-163.

[22] T. Schuller, D. Durox, S. Candel, Self-induced combustion oscillations of laminar premixed flames stabilized on annular burners, Combust. Flame 135 (4) (2003) 525-537.

[23] P. Palies, D. Durox, T. Schuller, S. Candel, Nonlinear combustion instability analysis based on the flame describing function applied to turbulent premixed swirling flames, Combust. Flame 158 (10) (2011) 1980-1991.

[24] M. Wagner, C. Jörg, T. Sattelmayer, Experimentally determining the acoustic damping rates of a combustor with a swirl stabilized lean premixed flame Proceedings of the ASME Turbo Expo 2013 (2013), pp. 1-11. GT2013-94844.

[25] G.J. Bloxsidge, A.P. Dowling, N. Hooper, P.J. Langhorne, Active control of an acoustically driven combustion instability, J. Mec. Theor. Appl. Suppl. 6 (1987) 161-175.

[26] W. Lang, T. Poinsot, S. Candel, Active control of combustion instability, Combust. Flame 70 (3) (1987) 281-289.

[27] T. Poinsot, B. Yip, D. Veynante, A. Trouve, J.M. Samaiego, S. Candel, Active control: an investigation method for combustion instabilities, J. Phys. III 2 (7) (1992) 1331-1357.

[28] K.R. McManus, T. Poinsot, S. Candel, A review of active control of combustion instabilities, Prog. Energy Combust. Sci. 19 (1) (1993) 1-29.

[29] A.M. Annaswamy, M. Fleifil, J.W. Rumsey, R. Prasanth, J.P. Hathout, A.F. Ghoniem, Thermoacoustic instability: model-based optimal control designs and experimental validation, IEEE Trans. Control Syst. Technol. 8 (6) (2000) 905-918.

[30] M.R. Bothien, J.P. Moeck, C.O. Paschereit, Comparison of linear stability analysis with experiments by actively tuning the acoustic boundary conditions of a premixed combustor, J. Eng. Gas Turb. Power 132 (12) (2010) 121502.

[31] M.A. Heckl, Active control of the noise from a rijke tube, J. Sound Vib. 124 (1) (1988) 117-133.

[32] N. Stadlmair, M. Wagner, C. Hirsch, T. Sattelmayer, Experimentally determining the acoustic damping rates of a combustor with a swirl stabilized lean premixed flame, Proceedings of ASME Turbo Expo 2015 (2015), pp. 1-10. GT201542683.

[33] L. Selle, T. Poinsot, B. Ferret, Experimental and numerical study of the accuracy of flame-speed measurements for methane/air combustion in a slot burner, Combust. Flame 158 (1) (2011) 146-154.

[34] R. Price, I. Hurle, T. Sugden, Optical studies of the generation of noise in turbulent flames, Symp. Combust. 12 (1) (1969) 1093-1102.

[35] D. Durox, T. Schuller, N. Noiray, A. Birbaud, S. Candel, Rayleigh criterion and acoustic energy balance in unconfined self-sustained oscillating flames, Combust. Flame 156 (1) (2009) 106-119.

[36] D. Mejia, Wall-temperature effects on flame response to acoustic oscillations, Université de Toulouse, 2014 Ph.D. thesis.

[37] D. Durox, T. Schuller, S. Candel, Self-induced instability of a premixed jet flame impinging on a plate, Proc. Combust. Inst. 29 (2002) 69-75. 